\title{
Relationship between Internet Addiction Anxiety and Loneliness among Young Adults in Mumbai
}

\author{
Shirin Plasterwala ${ }^{1}$, Anuja Deshpande ${ }^{2}$ \\ ${ }^{1,2}$ Assistant Professor, Department of Psychology, Maniben Nanavati Women's College, Mumbai. \\ Corresponding author: Anuja Deshpande \\ Email - dranujadeshpande18@gmail.com
}

\begin{abstract}
Background: The present study is empirical in nature and explores the relationship between internet addiction and anxiety, internet addiction and loneliness and anxiety and loneliness.

Methodology: Pearson Product Moment Correlation Coefficient was used to analyze whether any significant positive correlation exists amongst the variables. In this study 165 young adults age range of 1825 years living in Mumbai was administered the Internet Addiction Test, State Trait Anxiety Inventory, and UCLA Loneliness Scale Version 3.

Results: It was found that there was a significant positive correlation between internet addiction and anxiety, where the $r$ value was 0.266 which was significant at 0.01 level, i.e. $(r=.266, p<.01)$. A significant positive correlation was found between internet addiction and loneliness, where the $r$ value was 0.297 which was significant at 0.01 level, i.e. $(r=.297, \mathrm{p}<.01)$. A significant positive correlation was found between anxiety and loneliness, where the $r$ value was 0.646 which was significant at 0.01 level, i.e. $(r=.646, p<.01)$. Also, internet addiction was found to be predictor of anxiety $(\mathrm{R}=0.266, \mathrm{R} 2=0.71,(\mathrm{~F}=12.445)=.001$, sig). Internet Addiction was also found to be a predictor of loneliness $(R=0.297, R 2=0.88,(F=15.776)=.0001$, sig). Thus, the hypotheses of this study were validated.

Conclusions: Further studies in larger samples and diverse populations are needed to validate the findings of the current study.
\end{abstract}

Keywords: internet addiction, anxiety, loneliness, correlation, regression.

(Paper received $-13^{\text {th }}$ September 2021, Peer review completed $-15^{\text {th }}$ October 2021)

(Accepted $-28^{\text {th }}$ October 2021, Published $-5^{\text {th }}$ January 2022)

\section{INTRODUCTION}

The Internet is an integral part of human being's life in many ways, fun, play, gatherings are often arranged through internet. The internet has become important part in one's life. People are completely dependent on internet for even small things. People want their work to be done in minutes or as early as possible. Also, internet allow us to do that in no time our work is done, be it information transfer, emails, even our food now a days. With the use of internet our work is done under our fingertips. With the great easy advantages there are some disadvantages which should not be neglected. People are becoming dependent on internet for hours because everything has become easy and they do not have to do much of hard work. People spend long hours on internet due to which daily activities, academics are neglected. Family ties and friendships are loosened as priority is given to contacts established online. Students, teenagers, young adults are especially dependent on internet for their academics. Due to which they have become less creative in their work because naming someone else work as there is easy. Addiction leads people's experience sleeplessness, bad eating habits, lack of physical activity, anxiety, and loneliness.

People now feel satisfied in virtual world but in reality, they are lonely. Teenager and young adults most of them use internet in wrong ways. They satisfy themselves through pornography, cybercrimes, dating applications, but in real life they fail to maintain a healthy relationship in real consequences. Excessive use 
of internet also makes people more anxious in daily life. Too much time spent on laptops, mobile phones and computers may also create many health problems such as headaches, backaches, strained in eyes, muscles stiffness, and sleep problems. Due to excessive usage people are greater risks to many mental health concerns such as anxiety, depression, social isolation, impulse control problems, sleep problems, loneliness, irritable. There has been lot of empirical and theoretical investigations on the phenomenon of internet addition and its impact. Kathiat and Singh [1], conducted a meta-analytical study on internet usages at Indian scenario indicates an explosive growth in the use of internet not only worldwide but also in India in the last decade. There were about 42 million active internet users in urban India in 2008 as compared to 5 million in 2000. The internet is used by some to facilitate research, to seek information, for interpersonal communication, and for business transactions. On the other hand, it can be used by so-me to indulge in pornography, excessive gaming, chatting for long hours, and even gambling. There have been growing concerns worldwide for what has been labelled as "internet addiction". The total number of internet users in India is estimated to 81 million in the year 2010 (Internet usage stats and telecommunications market report). The profile of typical internet users in India are as follows: Youths (72\%), accessing internet through cyber cafes (37\%), with the purpose of checking mail (87\%) and for general information search (80\%).

\section{Internet Addiction}

Young [2] has described internet addiction as an impulse-control disorder that does not involve an intoxicant. Internet addiction is defined as any online related, compulsive behaviour which interferes with normal living and causes severe stress on family, friends, loved ones and one's work environment. Internet addiction has been called Internet dependency and Internet compulsivity. Shaw and Black [3] defined internet addiction as severe and uncontrollable obsession that an individual feels compulsion and shows compulsive behaviours. Internet addiction is a broad term that covers wide variety of behaviours and impulse control problems. It is categorized by five specific subtypes, and they are:

- Cyber sexual addiction: Compulsive use of adult websites for cybersex and cyber porn

- Cyber relationship addiction: over involvement in online relationships

- Net compulsions: obsessive online gambling, shopping or day trading

- Information Overload: Compulsive web surfing or database searches

- Computer Addiction: Obsessive computer game playing

\section{Anxiety}

According to American Psychological Association, Anxiety is an emotion characterized by feelings of tension, worried thoughts and physical changes like increased blood pressure. Anxiety is perceived as a state of emotional response that changes and is affected by subjective feelings of tension, stress and nervousness derived from the autonomous nervous system [4]. This response can be provoked by external and internal stimuli and is strongly influenced by the perception of the anxiety, the extent of fear one's senses and the duration of the incident [4].

\section{Loneliness}

Perlman and Peplau [5] defined loneliness are a common experience probably few people avoid being alone at some time in their life. It is also distressing experience as many individual's accounts bear out. Loneliness is defined as subjective, disagreeable, and unpleasant condition in which individuals perceive deficits in their social world [6]. Loneliness refers to the experience of isolation and to the feeling of deprivation in relation to others [7]. Loneliness is defined as the subjective experience of lack of connectedness, in terms of quantity and quality of social relations [8]. Some studies differentiate between emotional and social loneliness. Social loneliness refers to a person's lack of company and is related to the absence or a low number of close friends. Emotional loneliness indicates the lack of intimacy with close friends and has nothing to do with the number of friends. Some individuals may be socially isolated but not feel lonely, while other people feel lonely without feeling social isolation [9].

Internet addiction disorder is the result of defect cognition or defected cognitive processing and its treatment should be based on cognitive processes correction [10-11]. 
Bodhi and Kaur [12] did a study to determine psychological correlates internet addiction among college students which included 200 undergraduate college students. They used correlational analysis to study the relationship of internet addiction with depression anxiety, stress and total depression anxiety stress scale (DASS). The results revealed a significant and positive relationship of internet addiction with depression, anxiety, stress and total depression, anxiety, stress scale (DASS).

Mojgan Agah Heris and others [13], investigated the Relationship between Anxiety Physical and Subjective Symptoms amongst Students without and Exposed to Internet Addiction. results showed that high total grades of anxiety and its subscales (panic, autonomic, neurophysiological, and mental) amongst students who exposed Internet addiction in comparison to other groups. Master students showed high scores in Internet addiction compared to bachelor students. While there is no significant association between general anxiety, gender, and Internet addition. Younes and others [14] did a cross sectional study on internet addiction and relationships with insomnia, anxiety, depression, stress and self-esteem in 600 University students. The results revealed significant relationship between internet addiction and anxiety, insomnia, depression, stress and self-esteem.

Musarrat Azher and others [15], conducted a study on relationship between internet addiction and anxiety among college students of university of Sargodha. Regression analysis showed positive and significant relationship between internet addiction and level of anxiety among college students. Aghili and Aliniya [16] in the results of their study showed that internet addiction has negative correlation with positive aspects of psychological health (self-esteem and satisfaction with life) and positive correlation with negative aspects of psychological health (depression, anxiety and stress). Akin and Iskender [17], did a study to examine the relationship between internet addiction and depression, anxiety and stress among 300 college students. and found that internet addition is positively related to depression, anxiety and stress. Also, according to path analysis depression, anxiety and stress was predicted positively by internet addiction.

Salma Siyana and Ayesha Arif Zinna [18] examined loneliness, social support, life satisfaction and internet addiction among day scholars and hostel students in Chennai. The results revealed that internet addiction was significantly and positively correlated with loneliness and hostel students tend to have higher loneliness as compared to day scholars. Sharifpoor; Khademi; \& Mohammadzadeh [19], did a correlational study on internet addiction with loneliness and depression among high school students in Iran. Results showed significant correlation between loneliness and depression with internet addiction. Tabak and Zawadka [20], did a survey in Poland on loneliness and internet addiction of polish adolescents. The aim of the study was to assess the relationships between Internet addiction, loneliness (social and emotional) and adolescents' lower quality of life. Path analysis confirmed significant associations between Internet addiction and emotional loneliness and between emotional loneliness and quality of life. Emotional loneliness was statistically significant mediator between Internet addiction and quality of life.

Shahla Ostovar and others [21], did a cross sectional study on internet addiction and its psychological risks among Iranian adolescents and young adulthood. The results of this study showed that internet addiction is predictor for depression, anxiety, loneliness and stress. Furthermore, findings indicated that addictive internet use is gender sensitive and internet addiction is higher in males than in females.

Malik and Rafiq [22], did a study on role of personality traits (extraversion, introversion), loneliness and online social support in initiating internet addiction and its impact on procrastination. They found that there was no relevance of age, gender, and education to internet addiction. Neuroticism, social, loneliness, and online social support were found significantly positively related to internet addiction. Internet addiction was found significantly associated with procrastination after statistically controlling the effects of age, gender, neuroticism, loneliness, and online social support. Puri and Sharma (2016) found that increased in internet usage results in psychological problems like depression, loneliness, and social isolation.

\section{Objectives of the Study:}

- To study the relationship between Internet Addiction and Anxiety.

- To study the relationship between Internet Addiction and Loneliness.

- To study the relationship between Anxiety and Loneliness. 


\section{Hypotheses}

- Ha 1 There is a positive relationship between internet addiction and anxiety.

- Ha 2 There is a positive relationship between internet addiction and loneliness.

- Ha 3 There is a positive relationship between anxiety and loneliness.

\section{METHODOLOGY}

This study mainly explores the three major variables namely Internet addiction, Anxiety Loneliness while establishing the causal relationship between them by taking internet addition as the independent variable and Anxiety and Loneliness as the dependent variables. The sample for the study consisted of females and males within the age range of 18-25 years who use internet. A sample of 165 young adults was part of the study with 142 females and 23 males. In the present study judgment sampling was adopted where only those respondents were selected for the study who use internet in their phones, laptops, tablets and compute, understand English and belong to the age group of 18-25. The people who were living outside Mumbai were not considered for the study. In this study standard instruments were adopted such as Internet Addiction Test (IAT) [23], State Trait Anxiety Inventory (STAI) [24] and UCLA Loneliness Scale Version 3 [25]. The data were collected in person and through email. The study was conducted in Mumbai focusing on young adults in the age range of 18- 25 years of age. The data was collected from various colleges in Mumbai West Suburbs.

\section{RESULTS}

Table 1: Descriptive statistics table of Variables

\begin{tabular}{|l|l|l|l|}
\hline Descriptive Statistics \\
\hline & Mean & Std. Deviation & $\mathrm{N}$ \\
\hline Internet Addiction & 41.59 & 13.89 & 165 \\
\hline Anxiety & 45.72 & 8.42 & 165 \\
\hline Loneliness & 45.11 & 8.63 & 165 \\
\hline
\end{tabular}

The statistical properties of the variable are depicted in Table 1 for the entire sample. The Mean for Internet Addiction was 41.59 with Standard Deviation 13.89. The Mean for Anxiety was 45.72 with Standard Deviation 8.42. The Mean for Loneliness was 45.11 with Standard Deviation 8.63. Pearson's Product Moment Correlation was computed to assess the relationship between internet addiction and anxiety, internet addiction and loneliness and anxiety and loneliness. The Pearson correlation coefficient $r$ can take a range of values from +1 to -1 . A value of 0 indicates that there is no association between the two variables. A value greater than 0 indicates a positive association; that is, as the value of one variable increases, so does the value of the other variable. A value less than 0 indicates a negative association; that is, as the value of one variable increases, the value of the other variable decreases.

Table 2: Correlation Analysis between Internet addiction, anxiety and loneliness

\begin{tabular}{|c|c|c|c|c|}
\hline \multicolumn{2}{|c|}{} & Internet & Anxiety & Loneliness \\
\hline \multirow{3}{*}{ Internet } & Pearson Correlation & 1 & $.266^{* *}$ & $.297^{* *}$ \\
\cline { 2 - 5 } & Sig. (2-tailed) & & .001 & .000 \\
\cline { 2 - 5 } & $\mathrm{N}$ & 165 & 165 & 165 \\
\hline \multirow{3}{*}{ Lonxiety } & Pearson Correlation & $.266^{* *}$ & 1 & $.646^{* *}$ \\
\cline { 2 - 5 } & Sig. (2-tailed) & .001 & & .000 \\
\cline { 2 - 5 } & $\mathrm{N}$ & 165 & 165 & 165 \\
\hline & Pearson Correlation & $.297^{* *}$ & $.646^{* *}$ & 1 \\
\cline { 2 - 5 } & Sig. (2-tailed) & .000 & .000 & 165 \\
\cline { 2 - 5 } & $\mathrm{N}$ & 165 & 165 & 165 \\
\hline
\end{tabular}


The first hypothesis states that there is positive correlation between internet addiction and anxiety. From the table 2 it can be seen that the $r$ value was 0.266 which was significant at 0.01 level, i.e. $(r=0.266, p<0.01)$. Thus, the data supports the first hypothesis that there is a significant positive relationship between internet addiction and anxiety. The second hypothesis states that there is positive correlation between internet addiction and loneliness. From the table 2 it can be seen that $r$ value was 0.297 which was significant at 0.01 level, i.e. $(\mathrm{r}=.297, \mathrm{p}<.01)$. Thus, the data supports the second hypothesis that there is a significant positive relationship between internet addiction and loneliness. The third hypothesis states that there is positive correlation between anxiety and loneliness. From the table 2 it can be seen that $r$ value was 0.646 which was significant at 0.01 level, i.e. $(r=.646, \mathrm{p}<.01)$. Thus, the data supports the third hypothesis that there is a significant positive relationship between anxiety and loneliness.

Table 3: Regression Analysis for Internet addiction, anxiety and loneliness

\begin{tabular}{|l|l|l|l|l|}
\hline & R & R2 & F & Significance \\
\hline Anxiety & 0.266 & 0.071 & 12.455 & 0.001 \\
\hline Loneliness & 0.297 & 0.088 & 15.776 & 0.000 \\
\hline
\end{tabular}

Then the series of Regression Analysis were conducted to estimate the extent to which anxiety and loneliness could be predicted from internet addiction. The results revealed that Internet addiction can predict Anxiety significantly $(\mathrm{R}=0.266, \mathrm{R} 2=0.71,(\mathrm{~F}=12.445)=.001$, sig $)$. The results also revealed that Internet addiction can predict Loneliness significantly $(\mathrm{R}=0.297, \mathrm{R} 2=0.88,(\mathrm{~F}=15.776)=.0001$, sig $)$. Thus, it seems that Internet addiction can be used to predict anxiety and loneliness. Details of this regression analysis are presented in Table 3.

\section{DISCUSSION}

In the empirical investigation it was found that there is a significant relationship between internet addition, anxiety and loneliness. If a person has a high internet addiction they are very likely to have high anxiety and vice versa, If they have high anxiety they are very likely to also have high internet addiction. People these days are so much into their phones, constantly they are surfing,messaging, playing games or doing something or the other all time and many other important things are getting neglected.

The results have also indicated that if a person has high internet addiction they are very likely to have high loneliness and vice versa, if they have high loneliness they are very likely to have high internet addiction. People now a days make so much contacts in virtual world due to which family ties are getting small. They don't spend much time with people around them. Due to increased in using internet people have become lonely. They are not satisfied in reality but virtually they are satisfied.This hypothesis has also been validated by past researches. Similarly, if a person has high anxiety they are very likely to have high loneliness. It is possible that there is a high level of anxiety in individuals and lonely people are scared of messing up. They worry about saying the wrong thing in social situations. It could be that loneliness and social anxiety are intertwined, creating a vicious cycle of isolation and fear of being rejected. As individuals gets angry their circle tends to get smaller and they feel lonely. In the end, Regression analysis was done that internet addiction can be used to predict anxiety and loneliness. As seen in the results section, internet addiction is a significant predictor of anxiety and loneliness. This has been validated by past researches. The results of this research have been found to be in line with the hypotheses as well as past research on the relationship between internet addiction, anxiety, and loneliness. Thus, significant positive correlation has been found between internet addiction and anxiety, internet addiction and loneliness, anxiety, and loneliness. Also, internet addiction has been found to be significantly predictor of anxiety and loneliness.

\section{CONCLUSIONS}

This research adds to previous research which establish a significant relationship between internet addiction and anxiety, internet addiction and loneliness, anxiety, and loneliness. Since internet is facility that people 
are dependent right from checking information online to paying bills. People may not realize they are addicted to the internet and thus may not realize behaviour of the same. Thus, educational and awareness programs on internet addiction need to be created. Efforts can be made to educate people to create an internet schedule. Children and parents should be educated about internet addiction, its causes, and effects through workshop and awareness programs. Parents should monitor the internet use habits of their children's. It is important for mental health professionals to develop interventional strategies that prevent internet addiction. It is essential to examine both protective and risk factors for meaningful strategies. Individuals should be encouraged to make healthy and appropriate use of the internet as an invaluable tool for enhancing their academic and communication skills [26].

\section{REFERENCES}

1. Goswami V, Singh DR. İnternet addiction among adolescents: A review of the research. Int J Indian Psychol 2016;3(3):37-44.

2. Young KS. Internet addiction: A new clinical phenomenon and its consequences. Amer Behav Scientist 2004;48(4):402-15.

3. Shaw M, Black DW. Internet addiction. CNS Drug 2008;22(5):353-65.

4. Savci M, Aysan F. Relationship between impulsivity, social media usage and loneliness. Educ Process 2016;5(2):106-10.

5. Perlman D, Peplau LA. Toward a social psychology of loneliness. Personal Relat 1981;3:31-56.

6. Rotenberg KJ, MacDonald KJ, King EV. The relationship between loneliness and interpersonal trust during middle childhood. J Genet Psychol 2004;165(3):233-49.

7. Larose S, Guay F, Boivin M. Attachment, social support, and loneliness in young adulthood: A test of two models. Personal Soc Psychol Bull 2002;28(5):684-93.

8. Heinrich LM, Gullone E. The clinical significance of loneliness: A literature review. Clin Psychol Rev 2006;26(6):695-718.

9. Qualter P, Vanhalst J, Harris R, Van Roekel E, Lodder G, Bangee M, Maes M, Verhagen M. Loneliness across the life span. Perspect Psychol Sci 2015;10(2):250-64.

10. Yellowlees PM, Marks S. Problematic Internet use or Internet addiction?. Comp Hum Behav 2007;23(3):144753.

11. Young KS. Internet addiction: Evaluation and treatment. BMJ 1999;319(Suppl S4).

12. Bodhi V, Kaur J. Psychological correlates of internet addiction among college students. Indian Journal of Health and Wellbeing 2017;8(11):1404-8.

13. KhatibZanjani N, Agah Heris M. The prevalence of internet addiction among the students of Payam Noor University, Semnan Province. Interdisciplinary J Virtual Learning Med Sci 2014;5(2):1-7.

14. Younes F, Halawi G, Jabbour H, El Osta N, Karam L, Hajj A, Rabbaa Khabbaz L. Internet addiction and relationships with insomnia, anxiety, depression, stress and self-esteem in university students: A cross-sectional designed study. PloS One 2016;11(9):e0161126.

15. Azher M, Khan RB, Salim M, Bilal M, Hussain A, Haseeb M. The relationship between internet addiction and anxiety among students of University of Sargodha. Int J Hum Soc Sci 2014;4(1):288-93.

16. Aghili M, Aliniya R. Internet addiction and psychological health of students. Indian Journal of Health and Wellbeing 2013;4(7):1411-7.

17. Akin $\mathrm{A}$, Iskender $\mathrm{M}$. Internet addiction and depression, anxiety and stress. Int Online $\mathrm{J}$ Educ Sci 2011;3(1):138-48.

18. Ferraro G, Caci B, D'amico A, Blasi MD. Internet addiction disorder: an Italian study. Cyberpsychol Behav 2006;10(2):170-5.

19. Zhang S, Tian Y, Sui Y, Zhang D, Shi J, Wang P, Meng W, Si Y. Relationships between social support, loneliness, and internet addiction in Chinese postsecondary students: A longitudinal cross-lagged analysis. Front Psychol 2018;9:1707.

20. Tabak I, Zawadzka D. Loneliness and Internet addiction of Polish adolescents. Psychiatria i Psychologia Kliniczna 2017;17(2).

21. Ostovar S, Allahyar N, Aminpoor H, Moafian F, Nor MB, Griffiths MD. Internet addiction and its psychosocial risks (depression, anxiety, stress and loneliness) among Iranian adolescents and young adults: A structural equation model in a cross-sectional study. Int J Ment Health Addiction 2016;14(3):257-67.

22. Tahir MJ, Malik NI, Ullah I, Khan HR, Perveen S, Ramalho R, Siddiqi AR, Waheed S, Shalaby MM, De Berardis D, Jain S. Internet addiction and sleep quality among medical students during the COVID-19 pandemic: A multinational cross-sectional survey. PloS One 2021;16(11):e0259594. 
23. Young K. Internet addiction test (IAT). Stoelting; 2016 Dec 1.

24. Spielberger CD. State-Trait anxiety inventory. The Corsini encyclopedia of psychology. 2010 Jan 30:1-.

25. Russell DW. UCLA Loneliness Scale (Version 3): Reliability, validity, and factor structure. J Personal Assess 1996;66(1):20-40.

26. Afroz N. 2016. Internet addiction and subjective well- being of university students. Indian Journal of Health and Wellbeing 2016;7(8):787-94.

$* * * * * * * * * * * * * * * * * * * * * * * * * * * * * * * * * * * *$

Acknowledgements - Nil

Conflict of Interest - Nil

Funding - Nil 